\title{
Socio-Demographic Profile in Purchasing Natural and Synthetic Functional Foods in Malaysia
}

\author{
K. T. Phuah, G. Rezai, Z. Mohamed, and M. N. Shamsudin
}

\begin{abstract}
Functional foods represent one of the most interesting areas of research and innovation in the food industry. There are commercialized functional products in Malaysian market presently. Although the consumption of functional foods is increasing, relatively little is known about how consumers perceive these products and their buying frequency towards natural and synthetic functional foods in Malaysia. Therefore, the purpose of this study is to determine the relationship between socio-demographic variables and consumers' knowledge and buying frequency towards Natural and synthetic functional foods. Systematic random sampling was used in this study and 2004 households are interview by using structure questionnaire in Malaysia. Descriptive analysis and chi-square analysis were used in this study. The result shows that education level, area, income level, age and child under 18 years old have significant relationship with their knowledge to differentiate natural and synthetic functional foods. Moreover, the result also shows that marital status, area, education level, household size, age, income level and child under 18 years old have significant relationship with their purchasing behavior towards functional foods.
\end{abstract}

Index Terms-Knowledge, natural functional foods, purchasing, synthetic functional foods, socio-demographic profile.

\section{INTRODUCTION}

In 20th century, the advancement in research based on nutrition has discovered the required nutrients for the development, growth and maintenance of the human body. The concept of healthy and balanced diet have become the main driving force to support the elaboration of the dietary recommendations and food guidance [1]. Consumers began to view their diets from a different point of view. Food is no longer viewed to prevent diet-deficiency disease, satisfy hunger, provide nutrition such as water, protein, vitamins and minerals for maintenance or repair body tissue but it has become the primary component towards health and wellness. As the consumer interest in the relationships between diet, physical activity and health problems increase, health and wellness will continue to be the major global trend for the next 15 to 20 years [2].

Consumers are increasingly being more conscious to maintain a good health through diet, thereby consumers gravitating towards foods that offer additional benefits beyond that provided by conventional food and are

Manuscript received March 18, 2014; revised May 22, 2014

The authors are with the Department of Agribusiness and Information Systems, Faculty of Agriculture, Universiti Putra Malaysia, 43400 UPM Serdang, Selangor, Malaysia (e-mail: phuahkitteng@gmail.com, rgolnaz@putra.upm.edu.my, zam@agri.upm.edu.my, and nasir@agri.upm.edu.my). willingness to pay a premium for these products [3]. Currently, there is no global consensus concerning the meaning of functional foods [4]. A variety of term have been given worldwide to identify these food such as functional foods, nutraceuticals, medical foods, nutritional foods, pharma foods, healthy foods, wellness foods and fortify food and varies of efforts have been made by scientist and organization to define the meaning of the term [5]. According to American Dietetic Association [6], functional foods include conventional foods, modified foods such as fortified, enriched, or enhanced, medical foods, and foods for special dietary use. Functional foods are food that provides additional health benefits that may reduce disease risk or promote optimal health. Natural functional foods in this study refer to the foods that do not need any modification which are derived from natural sources such as Tongkat Ali, Ginseng, Chinese Wolfberry, Brahmi and Triphala [7]. Synthetic functional foods include modified food, medical food and food for special dietary use which are those foods that provide health benefits in addition to nutrient contributions rather than efforts to uncover the potential benefits of a single food source. Functional foods have a larger profit margin than conventional food and it is more expensive to the extent that the retail prices of functional foods are approximately 30 to 500 percent above the comparable conventional food [8]. Therefore, functional foods represent one of the most interesting area and innovation in the food industry [9]. However, functional foods market is still in an experimental phrase which characterized by a very high level of product failures even from experienced and well-established food companies such as Nestle [10].

Malaysia has a sizeable functional foods and drink market niche within its very large food and beverage market, which is now valued at more than RM 30 billion [11]. Currently, there are no dedicated tariff codes for functional foods in Malaysia because functional foods are still not officially defined [12]. According to the estimation done by Stanton $e t$ al., [11], functional foods in Malaysia now comprise about $30 \%$ and $40 \%$ of the total processed and retail packed food and drinks market and the segments with the greatest concentrations of functional products. However, there is no global definition for functional foods and consumers are often confused about the concept of functional foods [6]. There are also mix opinions between the consumption of natural and synthetic functional foods. A few nutritional authorities recognize and voice the concern that synthetic functional foods are not good for health and vice versa. There are also expert that encourage and promote consumer to consume natural functional foods. Given all the benefits of 
functional foods, the question is whether the Malaysian consumers have the knowledge to differentiate natural and synthetic functional foods. Furthermore, it is also important to know the consumer buying frequency on functional foods. Thus exploring and examining Malaysian consumers' knowledge and buying frequency towards natural and synthetic functional foods consumption is necessary in order to understand their food purchasing behavior.

\section{MATERIAL AND METHOD}

\section{A. Conceptual Framework}

Fig. 1 shows the conceptual framework of this study used to investigate the socio-demographic variables that influence consumers' knowledge and buying frequency towards functional foods. According to Pfannhauser [13], socio-demographic was stated as one of important factors that will affect consumers' food choice. On the other hand, many researchers have reported that socio-demographic profiles are relatively correlated to food purchasing behavior [13]-[15]. Therefore, socio-demographic profile such as marital status, area, household size, age, education level, gender, income and child under 18 are used in this study to determine the relationship between consumer knowledge and buying frequency and socio-demographic profile of consumers.

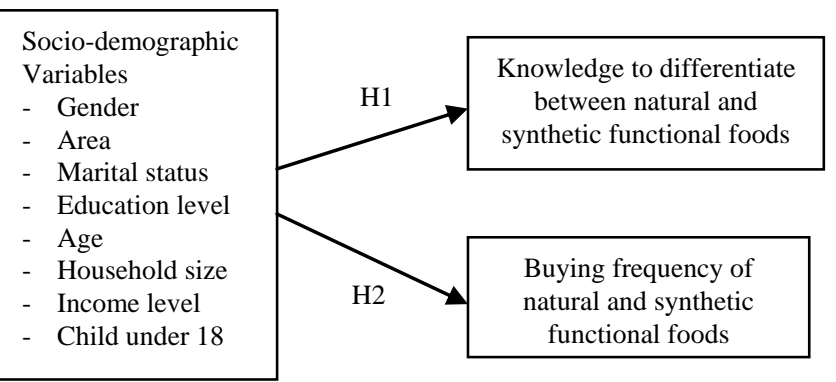

Fig. 1. Conceptual framework of consumer knowledge and buying frequency towards natural and synthetic functional foods.

\section{B. Research Hypotheses}

The focus of this research is to find a significant relationship between variables which influenced consumers' knowledge and buying frequency on natural and synthetic functional foods. Two hypotheses are tested in this study.

Hypothesis 1: There is no significant difference between respondents' socio-demographic profile and their knowledge of natural and synthetic functional foods.

Hypothesis 2: There is no significant difference between respondents' socio-demographic profile and consumer buying frequency on functional foods.

\section{Sample and Questionnaire}

The sample size in this study is 2004 households and the respondents were interviewed by using structure questionnaires to gather information on their knowledge and buying frequency towards natural and synthetic functional foods. The targeted respondents for this research are the household in Malaysia. The house units include the detach house, semi-detach house, terrace or link house, bungalow, flat, apartment and condominium. Systematic random sampling was used in this study which is based on the selection of units situated at a certain predetermined interval. Systematic random sampling was chose to use in this study because it is applicable for sample size which was approximately 1000 to 5000 basic sampling units (BSU) and the main advantages of using systematic random sampling was it can be used without having a list of basic sampling units as in a situations where the dwelling are well organized in rows, blocks or along a river or main road [16].

\section{Method of Analysis}

To accomplish the objective of this study, reliability test, descriptive analysis and Chi-Square analysis were performed. Reliability test means that the ability of the instrument to measure consistently reflects the construct it is meaning [17]. In this study, the Cronbach's Alpha was used to measure the reliability of 107 questions which were used to measure the consumer behavior towards natural and synthetic functional foods. Descriptive analysis is used to convert the quantitative data into a simpler summary to make it easier to analyze. Chi-square test of independence was used to test for statistical independence. In order to determine the statistical different of consumers' knowledge and buying frequency towards natural and synthetic functional foods and socio-demographic characteristic, two hypotheses have been set and tested in this study.

\section{RESUlTS}

The Cronbach's alpha value was 0.943 which means there was consistency among the conceptual framework items and therefore the model is fit for this study.

\section{A. Socio-Demographic Information}

Table I shows the socio-demographic profile of the respondents. The result showed that 53.6 percent was female and only 46.4 percent was males. Majority of the respondents were Malays (47.6 percent), followed by Chinese (32.5 percent), Indians (16.3 percent) and others such as Bajau, Bidayuh, Bugis, Melanau, Singh, Suluk, Kadazan, Dusun and Iban (3.6 percent). The numbers of respondents from urban and rural area were 59.6 percent and 40.4 percent respectively. From the two thousand and four respondents (2004), 38.9 percent were single and 61.1 percent respondents were married.

With regards to age and household size, the result showed that most of the respondents were between 26 to 35 years ( 33.8 percent) and 42.3 percent respondents have between 5 to 6 household size. The education level of the respondents is categorized into four categories which are primary education, secondary education, tertiary education and higher tertiary education. The result shows that majority of the respondents graduate from tertiary education (47.4 percent), 8.3 percent are primary educated, 26.7 percent are secondary school graduates and17.6 percent of the respondents are master and $\mathrm{PhD}$ holders. In terms of income distribution, this study found that majority of the respondents earned RM 3001 RM 4500 per month (34.1 percent) and only 5.9 percent of respondents had monthly income above RM 6001. Moreover, 
50.8 percent of respondents have children under 18 and 49.2 percent do not have children under 18 in their household.

TABLE I: SOCIO-DEMOGRAPHIC PROFILE OF RESPONDENTS ( $N=2004)$

\begin{tabular}{|c|c|c|c|}
\hline Characteristic & Percentage & Characteristic & Percentage \\
\hline Gender & & Education level & \\
\hline Male & 46.4 & Primary & 8.3 \\
\hline Female & 53.6 & Secondary & 26.7 \\
\hline Ethnic (Race) & & Tertiary & 47.4 \\
\hline Malay & 47.6 & Higher tertiary & 17.6 \\
\hline Chinese & 32.5 & Income level & \\
\hline Indian & 16.3 & Below 1500 & 19.4 \\
\hline Others & 3.6 & $1501-3000$ & 33.2 \\
\hline Area & & $3001-4500$ & 34.1 \\
\hline Urban & 59.6 & $4501-6000$ & 7.3 \\
\hline Suburban & 40.4 & Above 6001 & 5.9 \\
\hline Marital Status & & Age & \\
\hline Single & 38.9 & $18-25$ & 15.3 \\
\hline Married & 61.1 & $26-35$ & 33.8 \\
\hline Household size & & $36-45$ & 25.0 \\
\hline $1-2$ & 8.6 & $46-55$ & 15.4 \\
\hline $3-4$ & 26.7 & $56-65$ & 8.2 \\
\hline $5-6$ & 47.4 & 66 and Above & 2.2 \\
\hline \multirow[t]{3}{*}{7 and above } & 17.6 & Children under 18 & \\
\hline & & Yes & 50.8 \\
\hline & & No & 49.2 \\
\hline
\end{tabular}

\section{B. Chi-Square Analysis}

The results of Chi-square test indicate that some of the selected socio-demographic variables have significant relationship with consumers' knowledge and buying frequency towards natural and synthetic functional foods in Malaysia. Table II shows the chi-square value and the consumers' knowledge to differentiate between natural and synthetic functional foods. The result shows that area, education level, age, income level and child under 18 year old have significant different with their knowledge to differentiate natural and synthetic functional foods. The results showed that a significant relationship was found between the area and the respondent knowledge to differentiate between natural and synthetic functional foods in Malaysia. It shows that consumers from urban areas have more knowledge than consumers from suburban areas $\left(\chi^{2}=\right.$ $6.284, p<0.10)$. The results also shows that respondents who were younger ( 26 to 35 years old) $\left(\chi^{2}=18.073, p<0.01\right)$, have higher education level (at least tertiary education) $\left(\chi^{2}=\right.$ 23.449, $p<0.01)$ and higher income level $\left(\chi^{2}=19.463, p\right.$ $<0.01)$ can identify easier the two foods products. In terms of having child under 18 year old, respondents who have children under 18 years old have more knowledge towards natural and synthetic functional foods than others $\left(\chi^{2}=3.579\right.$, $p<0.10)$.

TABLE II: RELATIONSHIP BETWEEN DEMOGRAPHIC PROFILE AND KNOWLEDGE TO DIFFERENTIATE BETWEEN NATURAL AND SYNTHETIC FUNCTIONAL FOODS AMONG THE CONSUMERS

\begin{tabular}{cc}
\hline \hline Socio-demographic Variables & Chi-square \\
\hline Gender & 0.437 \\
Area & $9.424 * * *$ \\
Marital Status & 0.207 \\
Education Level & $23.449 * * *$ \\
Age & $18.073 * * *$ \\
House hold size & 2.531 \\
Income & $19.463 * * *$ \\
Child under 18 & $3.579 *$ \\
\hline \hline
\end{tabular}

***Statistically significant at the 0.01 level, ** 0.05 level and *0.10 level
The information presented in Table III shows the chi-square test results for the socio-demographic variables and respondent buying frequency of functional foods. The results show that respondents who have a higher education level (at least tertiary education) were more often to purchase functional foods than the respondents who have a low education level $\left(\chi^{2}=19.315, p<0.10\right)$. In terms of age and income level, respondents who are between 26 to 35 years old $\left(\chi^{2}=58.511, p<0.01\right)$ and have higher income level $\left(\chi^{2}=\right.$ $63.962, p<0.01)$ were more often to purchase functional foods. Furthermore, respondents who from urban area $\left(\chi^{2}=\right.$ 22.041, $p<0.01)$ have higher buying frequency than others respondents. In addition, the respondents who were married $\left(\chi^{2}=24.047, p<0.01\right)$, have children under 18 year old $\left(\chi^{2}=\right.$ $12.370, p<0.05)$ and have 5 to 6 household size $\left(\chi^{2}=35.010\right.$, $p<0.01)$ purchase functional foods more often than other respondents.

TABLE III: RELATIONSHIP BETWEEN DEMOGRAPHIC PROFILE AND BUYING FREQUENCY OF FUNCTIONAL FOODS AMONG THE CONSUMERS

\begin{tabular}{cc}
\hline \hline Socio-demographic Variables & Chi-square \\
\hline Gender & 2.011 \\
Area & $22.041^{* * *}$ \\
Marital Status & $24.047 * * *$ \\
Education Level & $19.315^{*}$ \\
Age & $52.604 * * *$ \\
House hold size & $35.010^{* * *}$ \\
Income & $63.962 * * *$ \\
Child under 18 & $12.370^{* *}$ \\
\hline \hline
\end{tabular}

*** Statistically significant at the 0.01 level, ** 0.05 level and *0.10 level

\section{DISCUSSION AND CONCLUSION}

Functional foods are becoming increasing importance for the food industry particularly in Malaysia. Some consumers believe that functional foods offer attributes such as meet recommended daily intake, create healthy diet, improve overall health, reduce the risk of disease or illness and improve skin condition. In this study, the results show that some socio-demographic characteristic will influence the consumer knowledge and buying frequency towards natural and synthetic functional foods. The study have similar results with the pass studies where functional foods consumers are mainly middle or old aged people [18], wealthy [14], married [15] and higher education level [19]. The results were similar with the previous study which shows that there was no gender difference toward purchasing functional foods [20]. From a marketing perspective, the ability to communicate the advantages and health benefits of both natural and synthetic functional foods is a key aspect to success in the functional foods industry. Knowledge towards functional foods is an important key factor that leads consumers towards functional foods and to have a healthy die. As recommendation, government and NGOs can implement information campaigns which play an important role in the development of functional foods. These campaigns should focus on providing more information on the advantage and benefits to consume natural and synthetic functional foods.

\section{REFERENCES}

[1] M. D. Barcellos and R. L. Lionello, "Consumer market for functional foods in South Brazil," International Journal of Food System Dynamics, vol. 2, no. 2, pp. 126-144, 2011. 
[2] C. M. Hasler, "The changing face of functional foods," Journal of the American College of Nutrition, vol. 19, no. 5, pp. 499-506, 2000.

[3] S. Mala, J. Hobbs, E. K. Sogah, and M. T. Yeung. (2013). Assessing the functional foods and natural health products industry: A comparative overview and literature review. [Online]. Available: http://www.aginnovation.usask.ca/cairn_briefs/publications\%20for\% 20download/Publication\%20

[4] American Dietetic Association, "Position of the American Dietetic Association: functional foods," Journal of American Dietetic Association, vol. 104, no. 5, pp. 814-826, 2004.

[5] N. M. Childs and G. H. Poryzees, "Foods that help prevent disease: Consumer attitudes and public policy implications," British Food Journal, vol. 100, no. 9, pp. 419-426, 1998.

[6] American Dietetic Association, "Position of the American Dietetic Association: functional foods," Journal of American Dietetic Association, vol. 1, pp. 735-746, 2009.

[7] European Union. (2010). Functional Foods. Studies and Repost. [Online]. Available: $\mathrm{ftp} / / / \mathrm{ftp}$.cordis.europa.eu/pub/fp7/kbbe/docs/functional-foods_en.pdf

[8] L. Kotilainen, R. Rajalahti, C. Ragasa, and E. Pehu, "Health enhancing foods opportunities for strengthening the sector in developing countries," The World Bank - Agricultural and Rural Development Discussion Paper 30, 2006.

[9] I. Sirò, E. Kapolna, B. Kapolna, and A. Lugasi, "Functional food product development, marketing and consumer acceptance-a review," Appetite, vol. 51, pp. 456-67, 2008.

[10] Just Food, "Global market review of functional foods-forecasts to 2013," Report. 2008.

[11] Stanton, Emms and Sia. (2011). Malaysia's markets for functional foods, nutraceuticals and organic foods: An introduction for Canadian producers and exporters. [Online]. Available: http://www.ats-sea.agr.gc.ca/ase/pdf/5842-eng.pdf

[12] Food and Agriculture Organization of the United Nations (FAO) Report on the regional expert consultation of the Asia-Pacific network for food and nutrition on functional foods and their implications in the daily diet, Regional Office for Asia and the Pacific, RAP Publication 2004/33, Bangkok, 2004

[13] W. Pfannhauser and M. Reichbart, "Consumer attitude and food choice," Report for Vienna, Austria, 2003.

[14] G. Turrell, B. Hewitt, C. Patterson, and B. Oldenburg, "Measuring socio-economic position in dietary research: Is choice of socio-economic indicator important?" Public Health Nutrition, vol. 6, no. 2, pp. 191-201, 2003.

[15] N. D. Jong, M. C. Ocke, H. A. C. Branderhorst, and R. Friele, "Demographic and life- style characteristics of functional food consumers and dietary supplement users," British Journal of Nutrition, vol. 89, pp. 273-281, 2003.

[16] Smart. (2012). Sampling method and sample size calculation for the smart methodology. [Online]. Available: http://assessments.humanitarianresponse.info/sites/assessments.human itarianresponse.info/files/Sampling_Paper_June_2012.pdf

[17] A. Field, Discovering Statistic Using SPSS: and Sex and Drugs and Rock ' $n$ ' Roll, 2nd ed. London: Sage Publication, 2005.

[18] J. B. Poulsen, "Danish consumers; attitude towards functional foods," Report for Centre for Market Surveillance, Research and Strategy for the Food Sector, Aarhus, Denmark, 1991.

[19] N. Wright and R. Lake, "Prevalence of vitamin and mineral supplement use amongst adults: A review of international literature," Journal of New Zealand Dietetic Association, vol. 52, no. 1, pp. 30-35, 1998

[20] D. Herath, J. Cranfield, and S. Henson, "Who consumes functional foods and nutraceuticals in Canada? Results of cluster analysis of the 2006 survey of Canadians' Demand for Food Products Supporting Health and Wellness," Appetite, vol. 51, pp. 256-265, 2008.

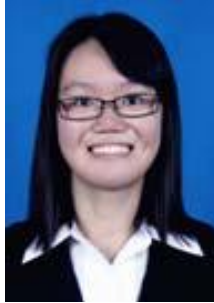

K. T. Phuah was born on November 13, 1987 in Ipoh, Perak, Malaysia. She obtains her undergraduate degree in bachelor science (agribusiness) from department of agribusiness and information systems, Faculty of Agriculture, Universiti Putra Malaysia, Selangor, Malaysia at October 2010. She continued her studies for a master of science (agribusiness) degree at the same Department. She obtained her master of science (agribusiness) degree on 12 July 2012. Currently, she continues her study on master of science (agribusiness) in University Putra Malaysia

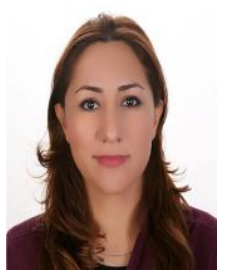

G. Rezai is a senior lecturer at the department of agribusiness marketing and information systems, Faculty of Agriculture and Information Systems, Universiti Putra Malaysia since May 2010. She obtained her undergraduate degree in food engineering from the Science and Research University Azhad Tehran, Iran in October 2002. She pursued her postgraduate studies in the field of agribusiness at Universiti Putra Malaysia and obtained her master of science (agribusiness) and $\mathrm{PhD}$. (agribusiness) in 2004 and 2008 respectively. After receiving her $\mathrm{PhD}$, she joined one of the FDA's pharmaceutical research in riverside, CA as a research fellow (integrated research group, 2008-2010). Her research interest is in the field of consumer behaviour and supply chain management in agribusiness. She has authored and co-authored 8 publications in journal articles, and conference proceedings, and presented about 20 papers in both local and international seminars in her area of expertise.

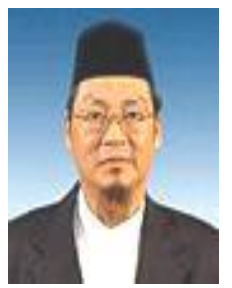

Z. Mohamed is a professor at the Department of Agribusiness and Information Systems, Faculty of Agriculture, Universiti Putra Malaysia since 1986. He holds a B.Sc (animal science) and M.Sc (agricultural economics) from University of Wyoming, USA and $\mathrm{Ph} . \mathrm{D}$. (agricultural economics) from Oklahoma State University, USA in 1985 . Currently he is heading the department of agribusiness and information systems which offers bachelor and master of science in agribusiness and master of science and $\mathrm{PhD}$. in agricultural economics. His research interest is in the area of agribusiness marketing management, market model and livestock economics. He has published articles in journals, proceedings and occasional papers. He has been teaching agribusiness and agricultural marketing courses to both graduate and undergraduate programs.

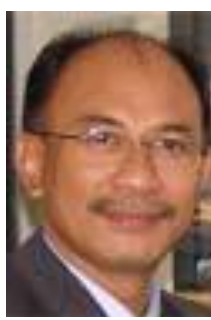

M. N. Shamsudin is a professor of agricultural and resource economics and the deputy vice chancellor (academic), Universiti Putra Malaysia. He received his B.S. degree in agricultural economics from Louisian State University, and $\mathrm{PhD}$ in agricultural economics and minor in statistics from Mississippi State University, USA. Professor Nasir has been teaching primarily in international agricultural trade, development economics, environmental economics, and managerial economics. His research areas of interest include international agricultural trade policy, commodity market analysis, and agro environmental economics. He has authored and co-authored more than 140 publications in books, book chapters, journal articles, and conference proceedings, and presented more than 100 papers in both local and international seminars in his area of expertise. 